\title{
Defect of Interferon $\gamma$ Leads to Impaired Wound Healing through Prolonged Neutrophilic Inflammatory Response and Enhanced MMP-2 Activation
}

Emi Kanno ${ }^{1, *(1)}$, Hiromasa Tanno ${ }^{1}$, Airi Masaki ${ }^{2}$, Ayako Sasaki ${ }^{2}$, Noriko Sato ${ }^{2}$, Maiko Goto ${ }^{1}$, Mayu Shisai ${ }^{1}$, Kenji Yamaguchi ${ }^{2}$, Naoyuki Takagi ${ }^{2}$, Miki Shoji ${ }^{2}$, Yuki Kitai ${ }^{3}$, Ko Sato ${ }^{4}$, Jun Kasamatsu ${ }^{4}$, Keiko Ishii ${ }^{3}$, Tomomitsu Miyasaka ${ }^{5}$, Kaori Kawakami ${ }^{5}$, Yoshimichi Imai ${ }^{2}{ }^{\mathbb{D}}$, Yoichiro Iwakura ${ }^{6}$, Ryoko Maruyama ${ }^{1}$, Masahiro Tachi ${ }^{2}$ and Kazuyoshi Kawakami ${ }^{3,4}$

1 Department of Science of Nursing Practice, Tohoku University Graduate School of Medicine, 2-1 Seiryo-cho, Aoba-ku, Sendai 9808575, Japan; hiromasa-tanno@med.tohoku.ac.jp (H.T.); skn.kdr.oor.325@gmail.com (M.G.); ambystomatmexicanum@gmail.com (M.S.); maruyama@med.tohoku.ac.jp (R.M.)

2 Department of Plastic and Reconstructive Surgery, Tohoku University Graduate School of Medicine, 2-1 Seiryo-cho, Aoba-ku, Sendai 9808575, Japan; masaki.a.m.825@gmail.com (A.M.); ssayakoss812@gmail.com (A.S.); surry310630@yahoo.co.jp (N.S.); jupiter1212@icloud.com (K.Y); takagi-prs@med.tohoku.ac.jp (N.T.); miki_shouji_0121@yahoo.co.jp (M.S.); yo-imai@med.tohoku.ac.jp (Y.I.); tachi@med.tohoku.ac.jp (M.T.)

3 Department of Medical Microbiology, Mycology and Immunology, Tohoku University Graduate School of Medicine, 2-1 Seiryo-cho, Aoba-ku, Sendai 9808575, Japan; kawakami@med.tohoku.ac.jp (K.K); yuki.m4058@gmail.com (Y.K.); ishii-k@med.tohoku.ac.jp (K.I.)

4 Department of Intelligent Network for Infection Control, Tohoku University Graduate School of Medicine, 2-1 Seiryo-cho, Aoba-ku, Sendai 9808575, Japan; ko-sato@med.tohoku.ac.jp (K.S.);

kasamatsu@med.tohoku.ac.jp (J.K)

5 Division of Pathophysiology, Department of Pharmaceutical Sciences, Faculty of Pharmaceutical Sciences, Tohoku Medical and Pharmaceutical University, Sendai 9818558, Japan; t-miya13@tohoku-mpu.ac.jp (T.M.); fl.nikomako.dr@gmail.com (K.K.)

6 Division of Laboratory Animals, Research Institute for Biomedical Sciences, Tokyo University of Science, 2669 Yamazaki, Noda, Chiba 2788510, Japan; iwakura@rs.tus.ac.jp

* Correspondence: ekanno@med.tohoku.ac.jp; Tel.: +81-22-717-8675

Received: 27 September 2019; Accepted: 10 November 2019; Published: 12 November 2019

\begin{abstract}
Interferon (IFN)- $\gamma$ is mainly secreted by CD4+ T helper 1 (Th1), natural killer (NK) and NKT cells after skin injury. Although IFN- $\gamma$ is well known regarding its inhibitory effects on collagen synthesis by fibroblasts in vitro, information is limited regarding its role in wound healing in vivo. In the present study, we analyzed how the defect of IFN- $\gamma$ affects wound healing. Full-thickness wounds were created on the backs of wild type (WT) C57BL/6 and IFN- $\gamma$-deficient (KO) mice. We analyzed the percent wound closure, wound breaking strength, accumulation of leukocytes, and expression levels of COL1A1, COL3A1, and matrix metalloproteinases (MMPs). IFN- $\gamma$ KO mice exhibited significant attenuation in wound closure on Day 10 and wound breaking strength on Day 14 after wound creation, characteristics that are associated with prolonged neutrophil accumulation. Expression levels of COL1A1 and COL3A1 mRNA were lower in IFN- $\gamma \mathrm{KO}$ than in WT mice, whereas expression levels of MMP-2 (gelatinase) mRNA were significantly greater in IFN- $\gamma \mathrm{KO}$ than in WT mice. Moreover, under neutropenic conditions created with anti-Gr-1 monoclonal antibodies, wound closure in IFN- $\gamma \mathrm{KO}$ mice was recovered through low MMP-2 expression levels. These results suggest that IFN- $\gamma$ may be involved in the proliferation and maturation stages of wound healing through the regulation of neutrophilic inflammatory responses.
\end{abstract}


Keywords: interferon- $\gamma$; wound healing; neutrophils; matrix metalloproteinase-2

\section{Introduction}

Wound healing is a complex process involving inflammation, cell proliferation, matrix deposition, and tissue remodeling [1,2]. During the inflammatory phase, infiltrating neutrophils and macrophages play an important role in the defense against bacterial infections and debridement of necrotic tissue [2]. In the proliferation phase, fibroblasts and myofibroblasts interact and produce extracellular matrix (mainly collagen), resulting in granulation tissue formation. The tissue remodeling process is associated with tissue maturation and collagen degradation by matrix metalloproteinases (MMPs), which are mainly derived from leukocytes and dermal fibroblasts [3]. Previously, several MMPs including MMP-2, $-8,-9$ and -13 have been reported to be involved in wound healing [4-7].

Neutrophils are the first infiltrating cells to appear within $24 \mathrm{~h}$ after wound creation and are necessary for host defense responses [8,9]. However, prolonged neutrophil infiltration is involved in the degradation of collagen by the production of proteinases such as MMPs. In-vitro collagen synthesis by fibroblasts is induced by transforming growth factor- $\beta$ (TGF- $\beta)[10,11]$ and inhibited by interferon $($ IFN)- $\gamma[12,13]$.

IFN- $\gamma$ is mainly secreted by CD4+ helper T cells, NK cells, and NKT cells and contributes to the activation of immune cells [14]. IFN- $\gamma$ is also associated with both neutrophil recruitment and cell clearance through apoptosis [15]. Indeed, in the thrombus resolution process, which resembles wound healing, the absence of IFN- $\gamma$ accelerates thrombus resolution by enhancing MMP-9 but not MMP-2 [16]. As for IFN- $\gamma^{\prime}$ s role in wound healing, in a mouse acute open wound model [14] and a post-scald burn injury model [17], IFN- $\gamma$ KO mice exhibited accelerated healing and enhanced TGF- $\beta$ expression compared with WT mice, suggesting that IFN- $\gamma$ makes a negative contribution to the skin wound healing process. While treatment with TNF- $\alpha$ plus IFN- $\gamma$-stimulated monocytes/macrophages in diabetic rat wounds improved the delay in wound healing [18], IFN- $\gamma^{\prime}$ s role in wound healing remains controversial.

With this background, we focused on the effects of IFN- $\gamma$ deficiency on the proliferation phase of skin wound healing using a mouse model with full-thickness wounds. Here, we show that IFN- $\gamma$ is required for the repair of skin wounds in the proliferation phase due to its regulation of neutrophilic inflammatory responses, including the activation of MMP-2 (Gelatinase A) which is mainly derived from neutrophils.

\section{Results}

\subsection{Delayed Wound Healing in IFN- $\gamma$-Deficient Mice in the Proliferative Phase}

To examine the possible contribution of IFN- $\gamma$ to wound healing, the rate of wound closure in IFN- $\gamma \mathrm{KO}$ mice was compared with that in WT mice. Wound closure on Day 10 was significantly delayed in IFN- $\gamma \mathrm{KO}$ mice compared with WT mice (Figure 1A,B). To confirm this effect, wound breaking strength was examined. Wound breaking strength on Day 14 was significantly delayed in IFN- $\gamma \mathrm{KO}$ mice compared with WT mice (Figure 1C). As an alternate indicator of wound healing, we also evaluated $\alpha$-SMA, which indicates myofibroblast differentiation. As shown in Figure 1D, the number of $\alpha-\mathrm{SMA}^{+}$cells was significantly decreased in IFN- $\gamma \mathrm{KO}$ mice. In addition, IFN- $\gamma \mathrm{KO}$ mice exhibited lower COL1A1, COL3A1, and TGF- $\beta 1$ expression compared with WT mice on Day 14 (Figure 1E). 
A

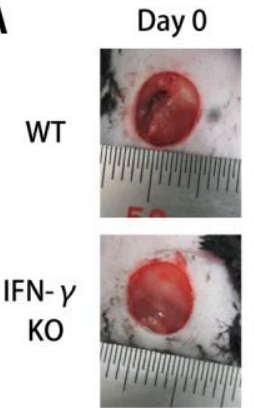

C

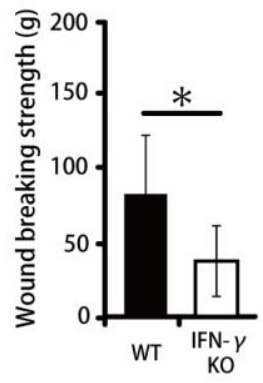

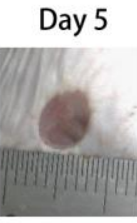

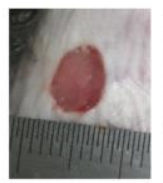

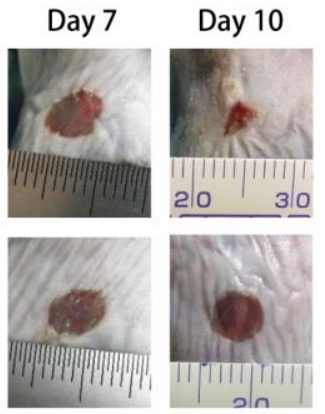

D $\quad$ a-SMA
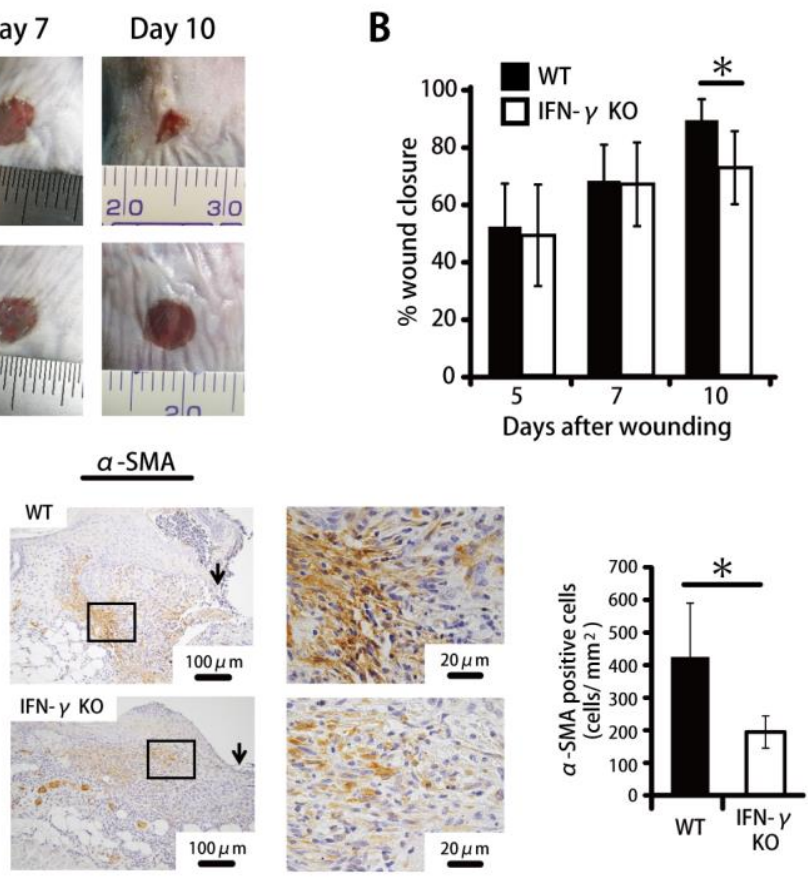

\section{E}
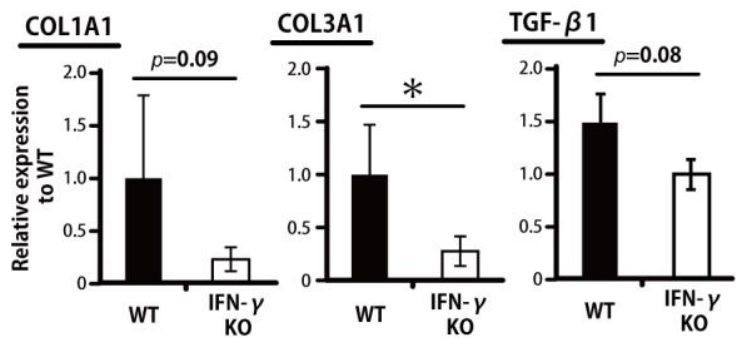

Figure 1. IFN- $\gamma$ deficiency leads to impaired wound healing in skin. Wounds were created on the backs of WT or IFN- $\gamma$ KO mice. (A) Wound photographs in WT or IFN- $\gamma$ KO mice. (B) Percentage of wound closure was evaluated on Days 5, 7, and 10. (C) Wound breaking strength was measured on day 14. (D) The number of myofibroblasts stained with anti- $\alpha$-SMA antibody on Day 10 . The myofibroblast density/mm2 was determined by counting the positive cells within six visual fields $(n=6)$. Arrows indicate the re-epithelialized leading edges. (E) Real-time PCR was performed to detect COL1A1, COL3A1, and TGF- $\beta$ mRNA isolated from the wound. Each column represents the mean \pm SD. ${ }^{*} p<0.05$.

\subsection{Prolonged Accumulation of Neutrophils in IFN- $\gamma$ KO Mice}

To define the role of inflammatory leukocytes during the wound healing process in IFN- $\gamma \mathrm{KO}$ mice, wounded skin tissues were histologically examined in IFN- $\gamma \mathrm{KO}$ and WT mice. As shown in Figure 2A, the former genotype exhibited prolonged accumulation of inflammatory leukocytes at the wound sites on Day 7. In the WT mice, in contrast, mainly fibroblasts were accumulated at the wound sites. Next, Ly6G, a marker specific to neutrophils, given that accumulated macrophages and eosinophils at the wound sites did not express Ly6G [19], was evaluated histologically. As shown in Figure $2 \mathrm{~B}$, the number of $\mathrm{Ly} 6 \mathrm{G}^{+}$cells on Day 7 was significantly greater in IFN- $\gamma \mathrm{KO}$ mice. Consistent with these results, CXCL1 (KC) and CXCL2 (MIP-2) expression levels were also significantly higher in IFN- $\gamma \mathrm{KO}$ mice than in WT mice on Day 7 (Figure 2C). 
A

A Day 7

WT
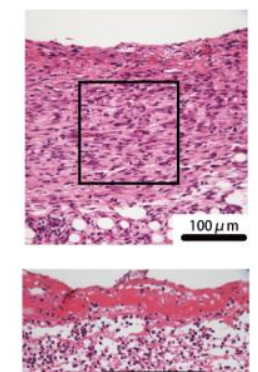

IFN- $y$ KO

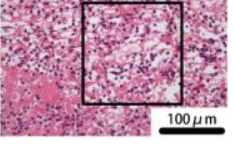

C

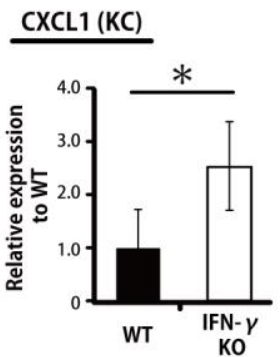

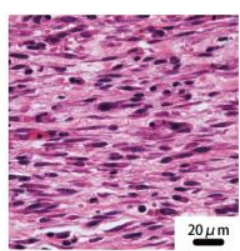

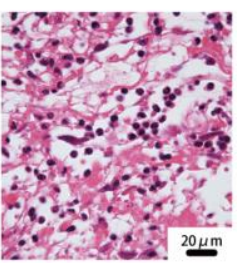

IFN- $y$ KO

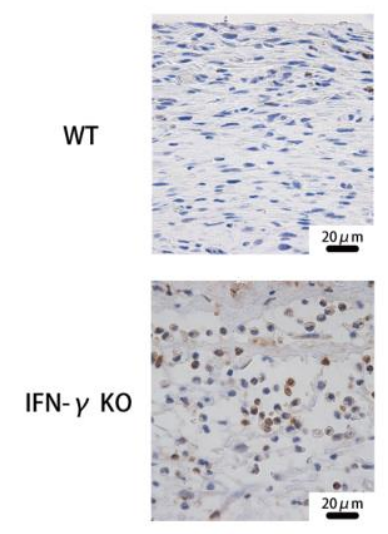

B

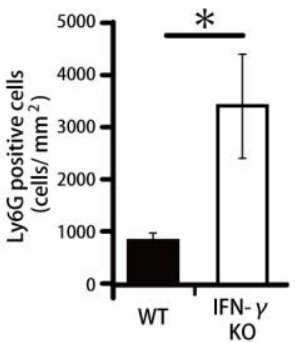

CXCL2 (MIP-2)

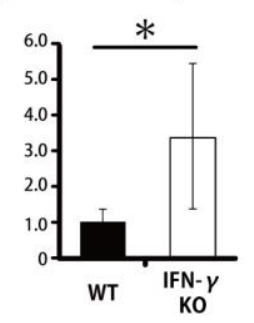

Figure 2. Prolonged accumulation of neutrophils in IFN- $\gamma-\mathrm{KO}$ mice. (A) Representative histological views of skin wounds on Day 7 are shown. (B) The number of neutrophils stained with anti-Ly6G antibody on Day 7. The Ly6G+ cell density/mm2 was determined by counting the positive cells in six visual fields $(n=6)$. (C) Real-time PCR was performed to detect CXCL1 (KC) and CXCL2 (MIP-2) mRNA isolated from the wound. Each column represents the mean \pm SD. ${ }^{*} p<0.05$.

\subsection{Inhibited MMP-2 Activation by IFN- $\gamma$}

To define the mechanisms underlying IFN- $\gamma$-associated reductions in breaking strength and in COL1A1 and COL3A1 expression as well as IFN- $\gamma$-associated prolonged neutrophil accumulation, we examined mRNA expression levels of the collagen degradation-associated factors $M M P-2$ and $M M P-9$ in the wounded tissue. MMP-2 mRNA expression on Day 14 was significantly increased in IFN- $\gamma \mathrm{KO}$ mice compared with WT mice; with regard to MMP-9 expression, in contrast, there was no significant difference between WT and IFN- $\gamma \mathrm{KO}$ mice (Figure 3A). As shown in Figure 3B, from a morphological perspective, $M M P-2$ is mainly expressed in neutrophils in IFN- $\gamma \mathrm{KO}$ mice in contrast to WT mice. Next, because MMP-2 expression was significantly increased in IFN- $\gamma \mathrm{KO}$ mice, we examined the involvement of IFN- $\gamma$ in the activity of neutrophil-derived MMP-2 and pro-MMP-2 activity by gelatin zymography. As shown in Figure 3C,D, pro-MMP-2 activity level was significantly suppressed by IFN- $\gamma$ in a concentration-dependent manner, while MMP-2 activity, in contrast, was not detected in any experimental groups. 
A
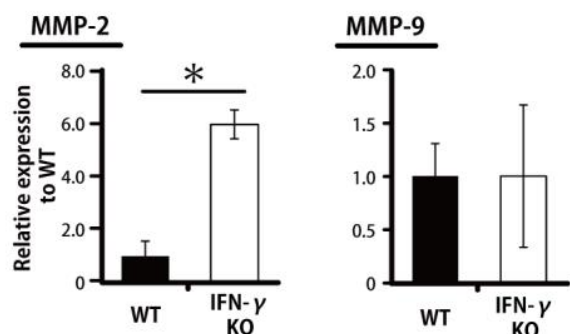

B
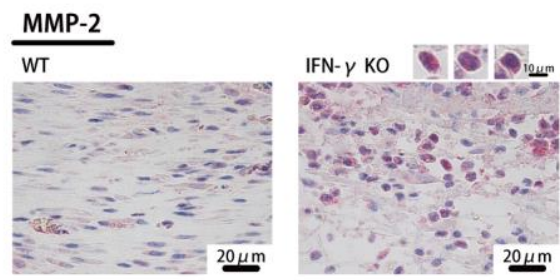

C
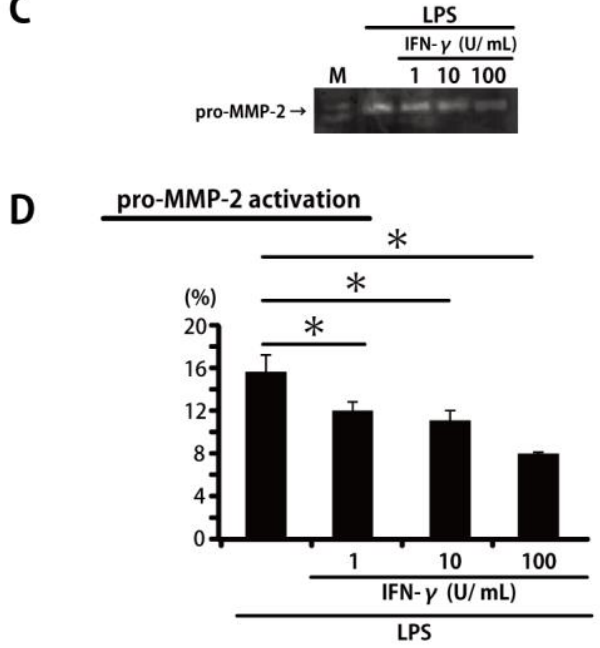

Figure 3. IFN- $\gamma$ leads to inhibited MMP-2 activation. (A) Real-time PCR was performed to detect MMP-2 and MMP-9 mRNA isolated from the wound. (B) Representative histological views of wounded skin stained with MMP-2 antibody on Day 7. Red indicates MMP-2 positive cells. (C) Thioglycolate-elicited peritoneal neutrophils were treated with IFN- $\gamma$ and lipopolysaccharide (LPS) for $24 \mathrm{~h}$. The conditioned medium samples were analyzed for pro-MMP-2 activation by gelatin zymography. (D) The levels of pro-MMP-2 activation in (C) were analyzed using Image J image analysis software. Each column represents the mean $\pm \mathrm{SD}$. ${ }^{*} p<0.05$. $\mathrm{M}$-marker.

2.4. Wound Healing and MMP-2 Expression after Neutrophil Depletion Induced by Anti-Gr-1 Monoclonal Antibody in IFN- $\gamma$ KO Mice

As histological findings have revealed, MMP-2 derived mainly from neutrophils is involved in the delayed wound healing in IFN- $\gamma \mathrm{KO}$ mice, as described above. Accordingly, we examined the effect of neutropenia induced by means of the anti-Gr-1 monoclonal antibody on wound closure and MMP-2 expression. As shown in our recent study [20], the neutrophils in peripheral blood are completely depleted by this treatment. Wound closure on Day 10 was significantly accelerated in anti-Gr-1 antibody-treated mice compared with control IgG-treated mice (Figure 4A). As shown in Figure $4 \mathrm{~B}, \mathrm{C}$, the accumulation of $\mathrm{Ly} 6 \mathrm{G}^{+}$neutrophils had almost completely disappeared on Day 10 after anti-Gr-1 antibody administration at the wound sites. In addition, MMP-2 expression was significantly decreased in anti-Gr-1 antibody-treated mice (Figure 4D). In the control group, interestingly, MMP-2 was mainly detected in infiltrating leukocytes, whereas MMP-2-expressing fibroblasts were frequently detected in the anti-Gr-1 antibody-treated group (Figure 4E). 
A

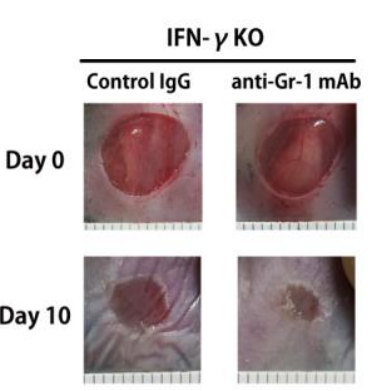

B

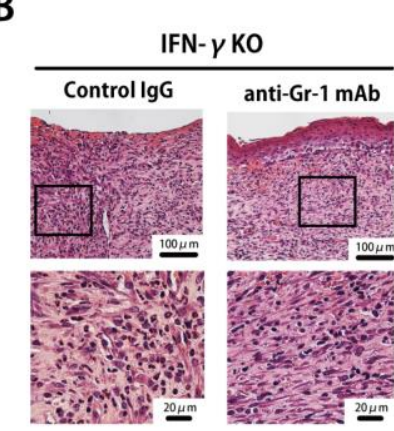

D

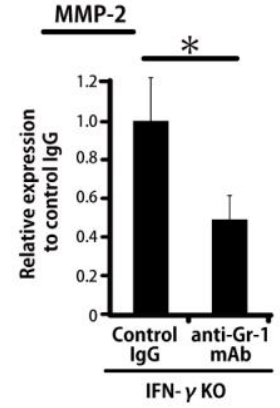

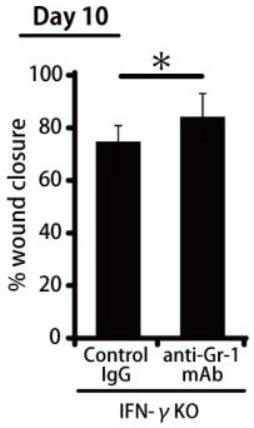

C

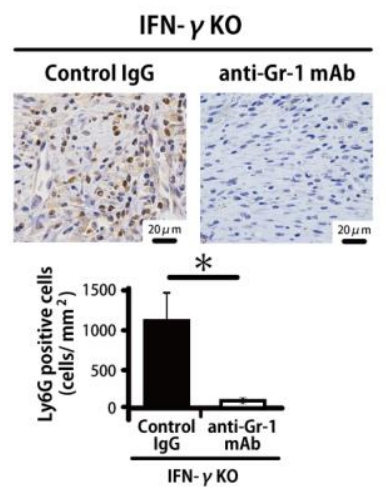

E

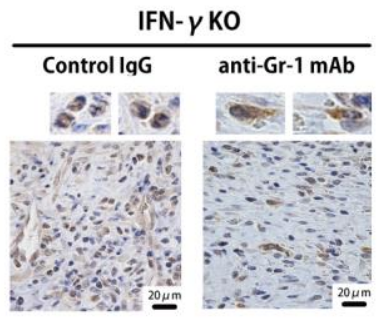

Figure 4. Neutrophil depletion by means of anti-Gr-1 monoclonal antibody leads to decreased MMP-2. (A) IFN- $\gamma \mathrm{KO}$ mice were injected intraperitoneally with anti-Gr-1 monoclonal antibody or control rat IgG 5 and 7 days after wound creation. Percentage of wound closure was evaluated on Day 10. (B) Representative histological views of skin wounds on Day 10 are shown. (C) The number of neutrophils stained with anti-Ly6G antibody on Day 10. The Ly6G+ cell density $/ \mathrm{mm}^{2}$ was determined by counting the positive cells in six visual fields $(n=6)$. (D) Real-time PCR was performed to detect $M M P-2$ mRNA isolated from the wound. (E) Representative histological views of wounded skin stained with MMP-2 antibody on Day 10. Each column represents the mean \pm SD. ${ }^{*} p<0.05$.

\section{Discussion}

In the current study, IFN- $\gamma \mathrm{KO}$ mice exhibited significant attenuation in wound closure, wound breaking strength, and myofibroblast differentiation in the proliferation phase compared with WT mice through prolonged neutrophil accumulation and enhanced MMP-2 activation.

IFN- $\gamma$ contributes to macrophage activation [14], neutrophil recruitment, and cell clearance by apoptosis [15]. Yet the question of how IFN- $\gamma$ contributes to wound healing, especially in the proliferative phase, remains controversial and poorly understood. Regarding the role of IFN- $\gamma$ in skin wounds, we previously reported that IFN- $\gamma$ plays a key role in the early phase of the wound healing process in a study on mice deficient in invariant natural killer $\mathrm{T}$ ( $i \mathrm{NKT}$ ) cells, which are major IFN- $\gamma$-producing cells [21]. In addition, IFN- $\gamma$-treated LEPCs, which initiate blood vessel regeneration [22], or TNF- $\alpha$ - and IFN- $\gamma$-treated monocytes/macrophages [18] have been reported to be involved in the promotion of wound healing. In the current study, IFN- $\gamma \mathrm{KO}$ mice exhibited significant 
attenuation in wound closure on Day 10 in association with prolonged neutrophil accumulation. In contrast to this, Ishida and Kondo et al. [14] demonstrated that IFN- $\gamma$ deficiency accelerated the wound healing process in association with an early-phase reduction in the infiltration of myeloperoxidase $(\mathrm{MPO})^{+}$neutrophils, $\mathrm{F} 4 / 80^{+}$macrophages, and $\mathrm{CD}^{+} \mathrm{T}$ cells.

Our murine wound model was at low risk for microbial infection as we used a clean procedure for the wounding and occlusive dressings for the wounds (closed wounds) until tissue collection. The model used by Ishida and Kondo et al. [14], in contrast, analyzed open wounds, i.e., wounds that had not been covered with occlusive dressings. This difference may have affected the different results of our two studies as a variation in environmental moisture and the microbial load at the wound site may have affected the findings. This possibility is strengthened by our previous finding that, compared with WT mice, IL-17AKO mice exhibited accelerated wound healing under closed-wound conditions but delayed wound healing under open-wound conditions [23].

In the present study, IFN- $\gamma \mathrm{KO}$ mice exhibited diminished wound breaking strength, reduced myofibroblast differentiation, and low levels of COL1A1 and COL3A1 expression. Although several reports have demonstrated that IFN- $\gamma$ can inhibit collagen synthesis by fibroblasts in vitro [12,13], in wound sites, IFN- $\gamma$ can contribute to collagen deposition [21]. Previously, Hata et al. reported that TGF- $\beta 1$ induces myofibroblast differentiation and collagen synthesis in the proliferation phase [24]. In this study, TGF- $\beta 1$ expression was decreased in IFN- $\gamma$ KO mice compared with WT mice. Thus, our results are likely to be related to a delay in collagen synthesis.

In the current study, IFN- $\gamma \mathrm{KO}$ mice exhibited delayed wound repair in the proliferative phase along with an increased neutrophil count, suggesting that accumulated neutrophils may suppress the healing process. In normal acute wounds, neutrophils are infiltrated immediately after skin injury and initially play a key role in antimicrobial activity; later, these cells undergo apoptosis and are engulfed by macrophages [25]. In non-healing wounds, however, prolonged neutrophil accumulation often leads to persistent inflammation through the production of proteases such as MMPs [26]. The functions of MMP-2 [6], MMP-8 [5], and MMP-9 [27] have been studied with regard to the wound healing process. MMP-2 is not considered to play a critical role in normal acute murine wounds [6]. In non-healing wounds in humans, however, high levels of MMP-2 activity have been detected [28]. In the current study, IFN- $\gamma \mathrm{KO}$ mice exhibited delayed wound healing associated with a significant increase in MMP-2 expression on recruited neutrophils at the wound sites. We also confirmed that pro-MMP-2 activity levels in peritoneal neutrophils were significantly suppressed by IFN- $\gamma$ stimulation. In fact, our current results demonstrate that delayed wound healing in IFN- $\gamma \mathrm{KO}$ mice can be recovered under neutropenic conditions induced by treatment with the anti-Gr-1 monoclonal antibody, and that this recovery is associated with low levels of MMP-2. Previously, Qin et al. [29] reported the transcriptional suppression of MMP-2 gene expression in human astroglioma cells by IFN- $\gamma$ administration. Our skin wound model likewise suggests that IFN- $\gamma$ could be involved in MMP-2 expression.

MMP-2 has been reported to involve tissue remodeling by degrading extracellular matrix components such as type III collagen, type IV collagen, fibronectin and elastin [30,31]. At wound sites, upregulation of $M M P-2$ expression has been observed in both granulation and scar tissues after skin injury [32]: during normal wound repair, $M M P-2$ expression reached peak levels on Day 3 after wound creation and declined thereafter to the baseline level [33]. In this study, we showed that IFN- $\gamma \mathrm{KO}$ mice exhibited decreased wound breaking strength along with upregulated MMP-2 activity, suggesting that MMP-2 in the proliferative phase may reduce the strength of wounded skin. Thus, MMP-2 is likely to contribute positively in the early phase of wound healing, and negatively from the proliferative phase onward.

In this study, our in vitro gelatin zymography experiment detected pro-MMP-2 activity but not MMP-2 itself in peritoneal neutrophils. It has previously been reported that MMP-2 is secreted as a zymogen (pro-MMP-2), and that membrane-bound MMP-14 (MT-1-MMP), which is mainly expressed on fibroblasts and cancer cells, activates secreted MMP-2 by cleaving its pro-domain [34]. Thus, 
the absence of MMP-14-expressing cells such as fibroblasts may be related to the absence of detectable MMP-2 in our in vitro analysis.

In conclusion, the present study demonstrated that IFN- $\gamma$ plays an important role in the proliferation phase of skin wound healing and in the neutrophilic inflammatory response at the wound site. To date, little was known about IFN- $\gamma^{\prime}$ s function in the proliferation phase; here, we have shown that it contributes significantly to wound strength and the suppression of inflammation. Inflammation is deeply involved in wound healing [35], but little is known about therapy for inflammatory responses at the wound sites. IFN- $\gamma$ therapy has already been used as a treatment for pulmonary fibrosis [36] and may also be useful in a novel approach to the treatment of augmented fibrosis in the skin, such as hypertrophic scarring, keloid scarring and scleroderma. However, we did not confirm the effects of IFN- $\gamma$ administration in this study. Further investigation is necessary to clarify the effects of IFN- $\gamma$ therapy on augmented fibrosis in skin as well as its optimal dose and route.

\section{Materials and Methods}

\subsection{Animals}

IFN- $\gamma$ gene-disrupted (knockout (KO)) mice were generated and established as described previously [37] and backcrossed to C57BL/6 mice for more than eight generations. Wild-type (WT) C57BL/6 mice, purchased from CLEA Japan (Tokyo, Japan), were used as controls. Male or female mice at 7 to 10 weeks of age were used in the experiments. Food and water were available ad libitum. All mice were kept under specific pathogen-free conditions in the Institute for Animal Experimentation, Tohoku University Graduate School of Medicine (Sendai, Japan). All experimental protocols described in the present study were approved by the Ethics Review Committee for Animal Experimentation of Tohoku University (2016MdA-279-3, 19 July 2016; 2016MdLMo-138-3, 7 July 2016). All experiments were performed under anesthesia, and all efforts were made to minimize suffering of the animals.

\subsection{Wound Creation and Tissue Collection}

All handling of the animals was performed under anesthesia induced by an intraperitoneal injection of $40 \mathrm{mg} / \mathrm{kg}$ sodium pentobarbital (Somnopentyl, Kyoritsu Seiyaku Corporation, Tokyo, Japan) and sustained by inhalation anesthesia of isoflurane (Isoflurane, Mairan Pharma, Osaka, Japan). The dorsal hair was shaved to fully expose the $\mathrm{n}$ skin, which was then rinsed with $70 \%$ ethanol. Four full-thickness wounds extending to the panniculus carnosus were created using a $6 \mathrm{~mm}$ diameter biopsy punch (Biopsy Punch, Kai industries Co., Ltd., Gifu, Japan) under sterile conditions. The injured areas were covered with a polyurethane film (Tegaderm Transparent Dressing, 3M Health Care, St. Paul, MN, USA) and an elastic adhesive bandage (Hilate, Iwatsuki, Tokyo, Japan) as an occlusive dressing. The day on which the wounds were made was designated as Day 0. At various time points, mice were sacrificed, and the wound tissue was collected by excising a $1 \mathrm{~cm}$ square section of skin using scissors and a surgical knife.

\subsection{Administration of Anti-Gr-1 Antibody and the Effect of Neutrophil Depletion Induced by This Means}

Anti-Gr-1 monoclonal antibody was purified from hybridoma culture supernatants (clones RB6-8C5) using a protein G column kit (Kirkegaard \& Perry Laboratories, Gaithersburg, MD, USA). To neutralize the biological activity of neutrophils, mice were injected intraperitoneally with $400 \mu \mathrm{g}$ of $\mathrm{mAb}$ on Days 5 and 7 after wounding. Rat IgG (ICN Pharmaceuticals, Aurora, OH, USA) was used as a control antibody. Immediately prior to injection and on Days 1, 2 and 5 after injection, mouse blood was collected via the tail vein and reacted with $0.83 \%$ ammonium chloride and Tris- $\mathrm{HCl}(\mathrm{pH} 7.2)$, then washed three times with 1\% FCS RPMI 1640 medium, yielding the blood cells used in our flow cytometric analysis. These blood cells were stained with PE-CD11b (BioLegend, San Diego, CA, USA) and APC/Cy7-anti-Ly6G mAb (clone 1A8; BioLegend). Isotype-matched irrelevant IgG was used 
for control staining. The stained cells were analyzed using a BD FACS Canto II flow cytometer (BD Bioscience, San Jose, CA, USA).

\subsection{Measurement of the Wound Area}

Morphometric analysis was performed on digital images obtained using a digital camera (CX4; Ricoh, Tokyo, Japan). After the wounds were created, photographs were taken of each wound before dressing. At various time points, the polyurethane films were gently removed from the experimental mice, and the wounds were photographed. Each wound area was quantified by tracing its margin and calculating the pixel area using AxioVision imaging software Release 4.6 (Carl Zeiss Micro Imaging Japan, Tokyo, Japan). Percentage of wound closure was calculated using the following formula: \% wound closure $=(1-$ wound area at the indicated time point $/$ wound area on Day 0$) \times 100$.

\subsection{Wound Breaking Strength}

Wounded skin tissue was harvested from WT and IFN- $\gamma \mathrm{KO}$ mice on Day 14 after wound creation. A strip of this tissue located $5 \mathrm{~mm}$ from the center of the wound was excised with a no. 15 surgical blade (Feather Safety Razor Co., Ltd., Osaka, Japan). Wound breaking strength was measured using an IMS-001 (Keisei Medical Industrial Co., Ltd., Tokyo, Japan) as previously described [38]. Briefly, each side of the strip was pinched in a clip and the two clips were pulled apart at a constant speed of $3 \mathrm{~cm} / \mathrm{min}$ until the strip broke. The result was expressed as the tensile force necessary to break the repaired wounds. Tensile force is characterized as tissue fragility and delay of collagen synthesis.

\subsection{Histology and Immunohistochemistry}

The tissues were fixed with $4 \%$ paraformaldehyde-phosphate buffer solution and embedded in paraffin. Sections were taken from the central portion of the wound and stained with hematoxylin-eosin (HE) according to the standard method.

For immunohistochemical analysis, after endogenous peroxidase was blocked with methanol/hydrogen peroxide, the sections were incubated with $10 \%$ normal rabbit serum for $20 \mathrm{~min}$ to block non-specific binding and then stained with anti- $\alpha$-smooth muscle actin ( $\alpha$-SMA) antibody (dilution 1:200; Vector Laboratories, Inc., Burlingame, CA, USA), anti-Ly6G Ab (clone 1A8; dilution 1:100; BioLegend), or anti-MMP-2 (dilution 1:200; Chemicon, Darmstadt, Germany). The sections were incubated with peroxidase-conjugated secondary $\mathrm{Ab}(4 \mu \mathrm{g} / \mathrm{mL}$; Histofine Simple Stain MAX-PO, Nichirei Bioscience, Tokyo, Japan), then reacted with 3, 3-diaminobenzidine (DAB) (Nichirei Bioscience) or Alkaline Phosphatase (Dako, Bettingen, Switzerland). The number of myofibroblasts and neutrophils in six random fields (each $0.2 \mathrm{~mm}^{2}$ ) was determined by counting the number of $\alpha$-SMA-positive cells or the number of Ly6G-positive cells, respectively. All analyses were performed under blinded conditions.

\subsection{RNA Extraction and Quantitative Real-Time RT-PCR}

Total RNA was extracted from the wound tissues using ISOGEN (Nippon Gene Co. Ltd., Tokyo, Japan), and first-strand cDNA was synthesized using the PrimeScript first-strand cDNA synthesis kit (TaKaRa Bio Inc., Otsu, Japan) according to the manufacturer's instructions. Quantitative real-time PCR was performed in a volume of $20 \mu \mathrm{L}$ using gene-specific primers and FastStart essential DNA green master mix (Roche Applied Science, Penzburg, Germany) in a Step One ${ }^{\mathrm{TM}}$ (Thermo Fisher Scientific, Waltham, MA, USA). Primers were as follows: 5' - TGT TCA GCT TTG ACC TCC G - $3^{\prime}$ (Forward) and 5' - TAC CTC GGG TTT CCA CGT CTC A -3' (Reverse) for COL1A1, 5' - GGA CCA GGC AAT GAT GGA AAA CC -3' (Forward) and 5' - ACC AGG GAA ACC CAT GAC ACC -3' (Reverse) for COL3A1, 5'-CCG CGC CTA TCG CCA ATG AGC TGC GC-3' (Forward) and 5'-CTT GGG GAC ACC TTT TAG CAT CTT TTG G-3' (Reverse) for CXCL1 (KC), $5^{\prime}$-CTG AAC AAA GGC AAG GCT AAC TG -3' (Forward) and 5'-CAC ATC AGG TAC GAT CCA GGC TT -3' (Reverse) for CXCL2 (MIP-2), $5^{\prime}$ - CCC CTG ATG TCC AGC AAG TAG A - $3^{\prime}$ (Forward) and $5^{\prime}$ - AGT CTG CGA TGA GCT TAG GGA AA-3' (Reverse) for MMP-2, 5' - CCC TGG AAC TCA CAC GAC ATC TTC-3' (Forward) and 
5'- GGT CCA CCT TGT TCA CCT CAT TTT -3' (Reverse) for MMP-9 and 5'-GCT TCC TCC TCA GAC CGC TT-3' (Forward) and 5' -TCG CTA ATC ACG ACG CTG GG-3' (Reverse) for $\beta$-actin (ACTB). The reaction efficiency with each primer set was determined using standard amplifications. Target gene expression levels and that of ACTB as a reference gene were calculated for each sample using the reaction efficiency. The results were analyzed using a relative quantification procedure and are presented as expression levels relative to that of ACTB.

\subsection{Isolation of Peritoneal Neutrophils}

Thioglycolate-elicited peritoneal neutrophils were obtained from WT mice by a previously described method [39]. WT mice were intraperitoneally injected with $1.5 \mathrm{~mL}$ of sterile $4 \%$ thioglycolate; 12-15 h later, peritoneal lavages were performed with $10 \mathrm{~mL}$ PBS in each mouse. The proportion of neutrophils in the lavages was over $90 \%$ as assessed by FACS analysis of anti-CD45, anti-CD11b, and anti-Ly6G expression. Peritoneal neutrophils were recovered by centrifugation and suspended in RPMI 1640 medium supplemented with 10\% FCS, $100 \mathrm{U} / \mathrm{mL}$ penicillin G, $100 \mu \mathrm{g} / \mathrm{mL}$ streptomycin, and $50 \mu \mathrm{M}$ 2-mercaptoethanol. The obtained cells were cultured at $1 \times 10^{6} / \mathrm{mL}$ with various doses of IFN- $\gamma$ or lipopolysaccharide (LPS) (Sigma-Aldrich, St. Louis, MO, USA) for $24 \mathrm{~h}$ at $37^{\circ} \mathrm{C}$.

\subsection{Pro-MMP-2 Assay}

Pro-MMP-2 activation in the culture supernatants, peritoneal neutrophils and IFN- $\gamma$ or LPS were measured using a gelatin zymography kit (Cosmo Bio, Tokyo, Japan) according to the manufacturer's instructions. The gelatin zymography products were electrophoresed on $2 \%$ agarose gels, stained with $0.5 \mathrm{mg} / \mathrm{mL}$ ethidium bromide and observed with a ultraviolet transilluminator. Images were analyzed using Image J version 1.51 (National Institutes of Health, MD, USA).

\subsection{Statistical Analysis}

Data are expressed as the mean \pm standard deviation (SD). Data analysis was performed using Welch's $t$-test. A $p$ value less than 0.05 was considered to indicate significance.

Author Contributions: In the present study, E.K., H.T., A.M. and A.S. performed the research, M.T. and K.K. designed the research study, N.S., M.G., M.S., K.Y., N.T., M.S., Y.K., K.S., J.K., K.I., T.M., K.K., Y.I. and R.M. analyzed the data, Y.I. contributed the knockout mice for the study, and E.K. and K.K. wrote the paper.

Funding: This work was supported in part by a Grant-in-aid for Scientific Research (B) (19H03918), a Grant-in-aid for Challenging Exploratory Research (17K19710) and a Grant-in-Aid for Young Scientists (19K19494) from the Ministry of Education, Culture, Sports, Science and Technology of Japan.

Conflicts of Interest: The authors have declared no conflicts of interest. The funders had no role in the design of the study; in the collection, analyses, or interpretation of data; in the writing of the manuscript, or in the decision to publish the results.

\begin{tabular}{ll}
\multicolumn{2}{l}{ Abbreviations } \\
$\alpha$-SMA & $\alpha$-smooth muscle actin \\
IFN- $\gamma$ & Interferon-gamma \\
KO & Knock out \\
MMP & Matrix metalloproteinase \\
NK cell & Natural killer cell \\
NKT cell & Natural killer T-cell \\
TGF- $\beta$ & Transforming growth factor beta \\
WT & Wild type \\
Th1 & T helper 1
\end{tabular}




\section{References}

1. Eming, S.A.; Krieg, T.; Davidson, J.M. Inflammation in wound repair: Molecular and cellular mechanisms. J. Investig. Dermatol. 2007, 127, 514-525. [CrossRef] [PubMed]

2. Martin, P.; Nunan, R. Cellular and molecular mechanisms of repair in acute and chronic wound healing. Br. J. Dermatol. 2015, 173, 370-378. [CrossRef] [PubMed]

3. Yamaguchi, Y.; Yoshikawa, K. Cutaneous wound healing: An update. J. Dermatol. 2001, 28, 521-534. [CrossRef] [PubMed]

4. Hattori, N.; Mochizuki, S.; Kishi, K.; Nakajima, T.; Takaishi, H.; D'Armiento, J.; Okada, Y. MMP-13 plays a role in keratinocyte migration, angiogenesis, and contraction in mouse skin wound healing. Am. J. Pathol. 2009, 175, 533-546. [CrossRef] [PubMed]

5. Gutiérrez-Fernández, A.; Inada, M.; Balbín, M.; Fueyo, A.; Pitiot, A.S.; Astudillo, A.; Hirose, K.; Hirata, M.; Shapiro, S.D.; Noël, A.; et al. Increased inflammation delays wound healing in mice deficient in collagenase-2 (MMP-8). FASEB J. 2007, 21, 2580-2591. [CrossRef] [PubMed]

6. Frøssing, S.; Rønø, B.; Hald, A.; Rømer, J.; Lund, L.R. Skin wound healing in MMP2-deficient and MMP2/plasminogen double-deficient mice. Exp. Dermatol. 2010, 19, e234-e240. [CrossRef] [PubMed]

7. Mäkelä, M.; Larjava, H.; Pirilä, E.; Maisi, P.; Salo, T.; Sorsa, T.; Uitto, V.J. Matrix metalloproteinase 2 (gelatinase A) is related to migration of keratinocytes. Exp. Cell Res. 1999, 251, 67-78. [CrossRef] [PubMed]

8. Park, J.E.; Barbul, A. Understanding the role of immune regulation in wound healing. Am. J. Surg. 2004, 187, 11S-16S. [CrossRef]

9. Dovi, J.V.; Szpaderska, A.M.; DiPietro, L.A. Neutrophil function in the healing wound: Adding insult to injury? Thromb. Haemost. 2004, 92, 275-280. [CrossRef] [PubMed]

10. Palumbo-Zerr, K.; Zerr, P.; Distler, A.; Fliehr, J.; Mancuso, R.; Huang, J.; Mielenz, D.; Tomcik, M.; Fürnrohr, B.G.; Scholtysek, C.; et al. Orphan nuclear receptor NR4A1 regulates transforming growth factor- $\beta$ signaling and fibrosis. Nat. Med. 2015, 21, 150-158. [CrossRef] [PubMed]

11. Barrientos, S.; Brem, H.; Stojadinovic, O.; Tomic-Canic, M. Clinical application of growth factors and cytokines in wound healing. Wound Repair Regen. 2014, 22, 569-578. [CrossRef] [PubMed]

12. Higashi, K.; Inagaki, Y.; Fujimori, K.; Nakao, A.; Kaneko, H.; Nakatsuka, I. Interferon- $\gamma$ interferes with transforming growth factor-beta signaling through direct interaction of YB-1 with Smad3. J. Biol. Chem. 2003, 278, 43470-43479. [CrossRef] [PubMed]

13. Harrop, A.R.; Ghahary, A.; Scott, P.G.; Forsyth, N.; Uji-Friedland, A.; Tredget, E.E. Regulation of collagen synthesis and mRNA expression in normal and hypertrophic scar fibroblasts in vitro by interferon- $\gamma$. J. Surg. Res. 1995, 58, 471-477. [CrossRef] [PubMed]

14. Ishida, Y.; Kondo, T.; Takayasu, T.; Iwakura, Y.; Mukaida, N. The essential involvement of cross-talk between IFN- $\gamma$ and TGF- $\beta$ in the skin wound-healing process. J. Immunol. 2004, 172, 1848-1855. [CrossRef] [PubMed]

15. McLoughlin, R.M.; Witowski, J.; Robson, R.L.; Wilkinson, T.S.; Hurst, S.M.; Williams, A.S.; Williams, J.D.; Rose-John, S.; Jones, S.A.; Topley, N. Interplay between IFN- $\gamma$ and IL-6 signaling governs neutrophil trafficking and apoptosis during acute inflammation. J. Clin. Investig. 2003, 112, 598-607. [CrossRef] [PubMed]

16. Nosaka, M.; Ishida, Y.; Kimura, A.; Kuninaka, Y.; Inui, M.; Mukaida, N.; Kondo, T. Absence of IFN- $\gamma$ accelerates thrombus resolution through enhanced MMP-9 and VEGF expression in mice. J. Clin. Investig. 2011, 121, 2911-2920. [CrossRef] [PubMed]

17. Shen, H.; Yao, P.; Lee, E.; Greenhalgh, D.; Soulika, A.M. Interferon- $\gamma$ inhibits healing post scald burn injury. Wound Repair Regen. 2012, 20, 580-591. [CrossRef] [PubMed]

18. Gu, X.; Shen, S.; Huang, C.; Liu, Y.; Chen, Y.; Luo, L.; Zeng, Y.; Wang, A. Effect of activated autologous monocytes/macrophages on wound healing in a rodent model of experimental diabetes. Diabetes Res. Clin. Pract. 2013, 102, 53-59. [CrossRef] [PubMed]

19. Daley, J.M.; Thomay, A.A.; Connolly, M.D.; Reichner, J.S.; Albina, J.E. Use of Ly6G-specific monoclonal antibody to deplete neutrophils in mice. J. Leukoc. Biol. 2008, 83, 64-70. [CrossRef] [PubMed]

20. Miura, T.; Kawakami, K.; Kanno, E.; Tanno, H.; Tada, H.; Sato, N.; Masaki, A.; Yokoyama, R.; Kawamura, K.; Kitai, Y.; et al. Dectin-2-mediated signaling leads to delayed skin wound healing through enhanced neutrophilic inflammatory response and neutrophil extracellular trap formation. J. Investig. Dermatol. 2019, 139, 702-711. [CrossRef] [PubMed] 
21. Tanno, H.; Kawakami, K.; Ritsu, M.; Kanno, E.; Suzuki, A.; Kamimatsuno, R.; Takagi, N.; Miyasaka, T.; Ishii, K.; Imai, Y.; et al. Contribution of invariant natural killer T cells to skin wound healing. Am. J. Pathol. 2015, 185, 3248-3257. [CrossRef] [PubMed]

22. Lee, B.N.R.; Chang, H.-K.; Son, Y.S.; Lee, D.; Kwon, S.-M.; Kim, P.-H.; Cho, J.-Y. IFN- $\gamma$ enhances the wound healing effect of late EPCs (LEPCs) via BST2-mediated adhesion to endothelial cells. FEBS Lett. 2018, 592, 1705-1715. [CrossRef] [PubMed]

23. Takagi, N.; Kawakami, K.; Kanno, E.; Tanno, H.; Takeda, A.; Ishii, K.; Imai, Y.; Iwakura, Y.; Tachi, M. IL-17A promotes neutrophilic inflammation and disturbs acute wound healing in skin. Exp. Dermatol. 2017, 26, 137-144. [CrossRef] [PubMed]

24. Hata, S.; Okamura, K.; Hatta, M.; Ishikawa, H.; Yamazaki, J. Proteolytic and non-proteolytic activation of keratinocyte-derived latent TGF- $\beta 1$ induces fibroblast differentiation in a wound-healing model using rat skin. J. Pharmacol. Sci. 2014, 124, 230-243. [CrossRef] [PubMed]

25. Wilgus, T.A.; Roy, S.; McDaniel, J.C. Neutrophils and wound repair: Positive actions and negative reactions. Adv. Wound Care 2013, 2, 379-388. [CrossRef] [PubMed]

26. Wetzler, C.; Kämpfer, H.; Stallmeyer, B.; Pfeilschifter, J.; Frank, S. Large and sustained induction of chemokines during impaired wound healing in the genetically diabetic mouse: Prolonged persistence of neutrophils and macrophages during the late phase of repair. J. Investig. Dermatol. 2000, 115, 245-253. [CrossRef] [PubMed]

27. Mohan, R.; Chintala, S.K.; Jung, J.C.; Villar, W.V.L.; McCabe, F.; Russo, L.A.; Lee, Y.; McCarthy, B.E.; Wollenberg, K.R.; Jester, J.V.; et al. Matrix metalloproteinase gelatinase B (MMP-9) coordinates and effects epithelial regeneration. J. Biol. Chem. 2002, 277, 2065-2072. [CrossRef] [PubMed]

28. Wysocki, A.B.; Staiano-Coico, L.; Grinnell, F. Wound fluid from chronic leg ulcers contains elevated levels of metalloproteinases MMP-2 and MMP-9. J. Investig. Dermatol. 1993, 101, 64-68. [CrossRef] [PubMed]

29. Qin, H.; Moellinger, J.D.; Wells, A.; Windsor, L.J.; Sun, Y.; Benveniste, E.N. Transcriptional suppression of matrix metalloproteinase- 2 gene expression in human astroglioma cells by TNF- $\alpha$ and IFN- $\gamma$. J. Immunol. 1998, 161, 6664-6673. [PubMed]

30. Itoh, T.; Matsuda, H.; Tanioka, M.; Kuwabara, K.; Itohara, S.; Suzuki, R. The role of matrix metalloproteinase-2 and matrix metalloproteinase-9 in antibody-induced arthritis. J. Immunol. 2002, 169, 2643-2647. [CrossRef] [PubMed]

31. Page-McCaw, A.; Ewald, A.J.; Werb, Z. Matrix metalloproteinases and the regulation of tissue remodelling. Nat. Rev. Mol. Cell Biol. 2007, 8, 221-233. [CrossRef] [PubMed]

32. Okada, A.; Tomasetto, C.; Lutz, Y.; Bellocq, J.P.; Rio, M.C.; Basset, P. Expression of matrix metalloproteinases during rat skin wound healing: Evidence that membrane type-1 matrix metalloproteinase is a stromal activator of pro-gelatinase A. J. Cell Biol. 1997, 137, 67-77. [CrossRef] [PubMed]

33. Soo, C.; Shaw, W.W.; Zhang, X.; Longaker, M.T.; Howard, E.W.; Ting, K. Differential expression of matrix metalloproteinases and their tissue-derived inhibitors in cutaneous wound repair. Plast. Reconstr. Surg. 2000, 105, 638-647. [CrossRef] [PubMed]

34. Oblander, S.A.; Zhou, Z.; Gálvez, B.G.; Starcher, B.; Shannon, J.M.; Durbeej, M.; Arroyo, A.G.; Tryggvason, K.; Apte, S.S. Distinctive functions of membrane type 1 matrix-metalloprotease (MT1-MMP or MMP-14) in lung and submandibular gland development are independent of its role in pro-MMP-2 activation. Dev. Biol. 2005, 277, 255-269. [CrossRef] [PubMed]

35. Beyer, S.; Koch, M.; Lee, Y.H.; Jung, F.; Blocki, A. An in vitro model of angiogenesis during wound healing provides insights into the complex role of cells and factors in the inflammatory and proliferation phase. Int. J. Mol. Sci. 2018, 19, 2913. [CrossRef] [PubMed]

36. Christmann, R.B.; Sampaio-Barros, P.; Stifano, G.; Borges, C.L.; de Carvalho, C.R.; Kairalla, R.; Parra, E.R.; Spira, A.; Simms, R.; Capellozzi, V.L.; et al. Association of Interferon- and transforming growth factor $\beta$-regulated genes and macrophage activation with systemic sclerosis-related progressive lung fibrosis. Arthritis Rheumatol. 2014, 66, 714-725. [CrossRef] [PubMed]

37. Tagawa, Y.; Sekikawa, K.; Iwakura, Y. Suppression of concanavalin A-induced hepatitis in IFN- $\gamma(-/-)$ mice, but not in TNF- $\alpha(-/-)$ mice: Role for IFN- $\gamma$ in activating apoptosis of hepatocytes. J. Immunol. 1997, 159, 1418-1428. [PubMed] 
38. Chen, L.; Mehta, N.D.; Zhao, Y.; DiPietro, L.A. Absence of CD4 or CD8 lymphocytes changes infiltration of inflammatory cells and profiles of cytokine expression in skin wounds, but does not impair healing. Exp. Dermatol. 2014, 23, 189-194. [CrossRef] [PubMed]

39. Baruah, S.; Murthy, S.; Keck, K.; Galvan, I.; Prichard, A.; Allen, L.-A.H.; Farrelly, M.; Klesney-Tait, J. TREM-1 regulates neutrophil chemotaxis by promoting NOX-dependent superoxide production. J. Leukoc. Biol. 2019, 105, 1195-1207. [CrossRef] [PubMed]

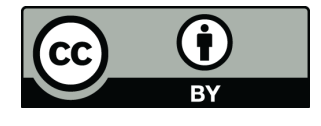

(C) 2019 by the authors. Licensee MDPI, Basel, Switzerland. This article is an open access article distributed under the terms and conditions of the Creative Commons Attribution (CC BY) license (http://creativecommons.org/licenses/by/4.0/). 